\title{
Ocular lesions in gerbils (Meriones unguiculatus) infected with low larval burden of Toxocara canis: observations using indirect binocular ophthalmoscopy
}

\author{
Lesões oculares em gerbils (Meriones unguiculatus) infectados \\ com baixo número de larvas do Toxocara canis: observações \\ com oftalmoscopia binocular indireta
}

\author{
Ledilma Inês Duarte Colodetti Zanandréa ${ }^{1}$, Gabriela Mantovanelli Oliveira ${ }^{1}$, \\ Andressa Silva Abreu ${ }^{1}$ and Fausto Edmundo Lima Pereira ${ }^{1}$
}

\begin{abstract}
To study the frequency of ocular lesions in 30 gerbils infected with 100 embryonated eggs of Toxocara canis, indirect binocular ophthalmoscopy was performed 3, 10, 17, 24, 31 and 38 days after infection. All the animals presented larvae in the tissues and $80 \%$ presented ocular lesions. Hemorrhagic foci in the choroid and retina were present in $92 \%$ of the animals with ocular lesions. Retinal exudative lesions, vitreous lesions, vasculitis and retinal detachment were less frequent. Mobile larvae or larval tracks were observed in four (13.3\%) animals. Histological examination confirmed the ophthalmoscopic observations, showing that the lesions were focal and sparse. In one animal, there was a larva in the retina, without inflammatory reaction around it. The results demonstrated that gerbils presented frequent ocular lesions after infection with Toxocara canis, even when infected with a small number of embryonated eggs. The lesions observed were focal, consisting mainly of hemorrhages with signs of reabsorption or inflammation in different segments of eye, and differing from the granulomatous lesions described in ocular larva migrans in humans.
\end{abstract}

Key-words: Ocular toxocariasis. Ocular larva migrans. Toxocariasis. Toxocara canis. Gerbils.

\section{RESUMO}

Para verificar a freqüência de lesões oculares em 30 gerbils infectados com 100 ovos larvados de Toxocara canis foi realizada a oftalmoscopia binocular indireta nos dias 3, 10, 17, 24, 31 e 38 após a infecção.Todos os animais apresentavam larvas nos tecidos e 80\% apresentavam lesões oculares, dos quais $92 \%$ tinham lesões hemorrágicas focais na coróide e na retina. Lesões exudativas da retina, lesões do vítreo, vasculite e descolamento da retina foram menos freqüentes. Larva móvel ou traços de larva em quatro (13,3\%) animais. 0 estudo histológico confirmou as observações da oftalmoscopia, mostrando que as lesões eram focais e esparsas. Em um animal havia uma larva na retina, sem reação inflamatória em torno dela. Os resultados demonstraram que os gerbils apresentam freqüentes lesões oculares após infecção com o Toxocara canis mesmo quando infectados com pequeno número de ovos larvados. As lesões observadas eram focais, principalmente focos de hemorragia com sinais de reabsorção ou focos de inflamação nos diferentes segmentos do olho, diferentes das lesões granulomatosas descritas na larva migrans ocular humana.

Palavras-chaves: Toxocaríase ocular. Larva migrans ocular. Toxocaríase. Toxocara canis. Gerbils.

Toxocariasis is an intestinal parasitosis produced by worms belonging to the genus Toxocara, frequently in dogs (Toxocara canis) and cats (Toxocara cati), in which the adult worms live in the small intestine. Man is a paratenic host in which the ingested eggs deliver larvae into the intestine, from where the larvae migrate to the blood stream, thereby reaching different organs in which they may be killed by granulomatous inflammation around them or may stay in a dormant state for several years ${ }^{619}$.
Human tissue invasion by Toxocara larvae is an anthropozoonosis with universal distribution, but is more prevalent in developing countries ${ }^{111828}$. The clinical manifestations of the infection are variable, from asymptomatic infections to fully developed syndromes of visceral or ocular larva migrans $^{11} 181920$. Isolated cases of neurotoxocariasis ${ }^{22}$, Toxocara myocarditis ${ }^{1}$ and undefined clinical forms (covert toxocariasis) have been reported ${ }^{29}$.

\footnotetext{
1. Núcleo de Doenças Infecciosas, Centro de Ciências da Saúde, Universidade Federal do Espírito Santo, Vitória, ES.

Address to: Dr. Fausto E.L. Pereira. Núcleo de Doenças Infecciosas/CCS/UFES. Av. Marechal Campos 1468, 29040-091 Vitória, ES.

Fax: 5527 3335-7204

e-mail felp@ndi.ufes.br

Recebido para publicação em 26/10/2007

Aceito em 09/10/2008
} 
Human toxocariasis is diagnosed through its clinical manifestations in the classical forms of ocular or visceral larva migrans, and through detection of anti-Toxocara antibodies in serum or, less frequently, through identification of Toxocara larvae in tissues. Classical visceral larva migrans is associated with high eosinophil counts, hepatosplenomegaly, focal pulmonary condensations and high titers of anti-Toxocara antibodies ${ }^{1125}$. Computed tomography, magnetic resonance or ultrasonography may demonstrate granulomatous lesions in liver parenchyma ${ }^{458}$. In liver biopsies or in autopsied cases, eosinophil-rich granulomas with Toxocara antigens have been reported, demonstrated by immunohistochemistry ${ }^{923}$.

Ocular larva migrans occurs when Toxocara larvae reach eyeball tissues, where they induce inflammatory reactions, frequently without the signs or symptoms that accompany the visceral larva migrans syndrome ${ }^{13152126}$. It was first reported 50 years ago, when Wilder ${ }^{30}$ reported findings of helminth larvae during histological observations of enucleated eyeballs with tumor-like lesions. Years later, these were confirmed to be Toxocara larvae after morphology studies by Nichols ${ }^{24}$. Since this time, several cases of ocular larva migrans have been reported in different countries, most frequently in children and adolescents, with unilateral lesions ${ }^{13152126}$. The most frequent lesion types are diffuse endophthalmitis, posterior pole granuloma, peripheral inflammatory mass, diffuse unilateral subacute neuroretinitis and presence of mobile larva in the chorioretina ${ }^{21}$.

The diagnosis of ocular larva migrans is based on retinoscopic and retinographic studies, and is confirmed by findings of larvae in lesions. Eosinophilia is slight or absent and anti-Toxocara antibodies in serum frequently have low titers ${ }^{1320}$. However, searching for anti-Toxocara antibodies or antigens in eye fluids (aqueous or vitreous humors) has been reported to be a sensitive method for detecting ocular infection by Toxocara larvae in experimental and human infections ${ }^{720}$. It is accepted that ocular toxocariasis occurs after migration of small numbers of larvae from the intestine, thereby inducing a weak immune response that favors their ocular localization, with few systemic manifestations ${ }^{14}$.

Experimental studies on ocular lesions induced by Toxocara larvae have been reported using mice, rats, rabbits, guinea pigs, non-human primates and, most recently, in gerbils ${ }^{12}$. Mice are frequently used as experimental animals for Toxocara infection but in these animals, the cornea dries easily and becomes cloudy, making ophthalmoscopic observations difficult ${ }^{27}$.

Gerbils have been described as useful animals for experimentally studying ocular toxocariasis because, apart from their high susceptibility to the infection, they have big eyes with pigmented retina, thus allowing direct examination by means of ophthalmoscopy ${ }^{27}$.

There are few reports on ophthalmic lesions in gerbils infected with Toxocara canis ${ }^{31627}$ or Toxocara cati ${ }^{2}$, and all of them used heavy infections of more than 1000 embryonated eggs per animal. Since ocular toxocariasis is accepted to be more frequent after acquiring a low larval burden ${ }^{14}$, we decided to study ocular lesions in gerbils infected with a small number of Toxocara eggs, by means of binocular indirect ophthalmoscopy.

\section{MATERIAL AND METHODS}

Outbred gerbils (Meriones unguiculatus), five to six months old ( 15 male and 15 female), were used in the experiments. The animals were purchased from a local breeder and were kept, one or two per cage, at ambient temperature, receiving water and balanced food ad libitum.

The animals were manipulated in accordance with the ethical principles of animal experimentation from the International Union of Animal Protection.

Toxocara eggs were obtained after collecting female adult worms from the intestines of dogs subjected to necropsy at the Center for Zoonosis Control in Vitória, Espírito Santo, Brazil. After washing with tap water, female worms were sectioned at the extremities and pressed with a forceps to release the ovaries, which were chopped with scissors in a Petri dish with saline. The suspension of eggs and ovary fragments was filtered through a nylon mesh and the eggs that were collected were incubated in $2 \%$ formaldehyde, at $28^{\circ} \mathrm{C}$. After six weeks, the eggs were washed three times in saline and the number of eggs with mobile larvae was counted in a McMaster chamber. The egg suspension was adjusted to a concentration of 200 embryonated eggs with mobile larvae per $\mathrm{ml}$.

The gerbils were infected by means of gavaging using an appropriate needle, and each animal received 100 embryonated eggs in a volume of $0.5 \mathrm{ml}$.

Binocular indirect ophthalmoscopy was performed after administering light anesthesia with ether and dilatation of pupils with one drop of $1 \%$ tropicamide in each eye. A binocular ophthalmoscope with an OHD-4.2 camera (EYE-TEC Equipamentos Oftálmicos, São Carlos, SP, Brazil) coupled to a high-resolution digital color video system was used. A 30-diopter Volk lens for small eyes was used and all examinations were performed under low illumination in the room. The images were captured and recorded in a $\mathrm{PC}$, using a Dazzle-Pinnacle capture system. All the animals were examined before the inoculum and on days 3,10 , 17, 24, 31 and 38 after infection.

After the last ophthalmoscopic examination (38 days postinfection) all the animals were killed by means of intraperitoneal injection of a lethal dose of pentobarbital. The animals were subjected to necropsy for confirmation of infection by direct examination of liver fragments pressed between two slides or by examination of hematoxylin and eosin-stained paraffin sections of liver, lungs and encephalon. The eyeballs were enucleated, fixed in $10 \%$ formaldehyde, sectioned in the sagittal plane and embedded in paraffin, and the sections were stained with hematoxylin and eosin.

\section{RESULTS}

Before infection, the gerbil's eyegrounds presented optical discs with or without pigments, sharp blood vessels and reddish retina, allowing excellent visualization, especially in animals with pigmented hair. 
The main abnormalities observed before infection were small, multiple white spots in the eyeground (30\% of the animals) and areas of rarefaction of pigment epithelium, which were more visible in animals with yellow or white hair. Vitreous asteroid hyalosis and coloboma of the optic disk and a hole in the retina were observed in one animal.

Six animals died within three weeks because of anesthesia.

Twenty-four animals presented ocular lesions observed by means of ophthalmoscopy (five out of the six that accidentally died and 19 out of the 24 that survived until 38 days after infection). The main ocular lesions observed through ophthalmoscopy are shown in Tables 1 and 2, and in Figure 1. There was no gender difference in the frequencies of retinal lesions $(13 / 15$ or $86.7 \%$ in males and $11 / 15$ or $73.3 \%$ in females; $\mathrm{p}=0.651$ ).

Ocular lesions started to appear in the first week and, after four weeks, they were present in $80 \%$ of the animals. However, they were not observed in six animals (20\%) until 38 days postinfection.

The hemorrhagic lesions frequently showed signs of involution one week after they were observed. For this reason, when the animals were examined 38 days after infection, the majority of the hemorrhagic lesions showed a pattern of involution.

The lesions were bilateral in $40 \%$ of the animals and were more frequent in the lower areas of the eyeball (inferior temporal and nasal regions; 46 and $42.5 \%$, respectively) and at the posterior pole (46\%), while they were less frequent in the superior temporal and nasal regions ( $23 \%$ of the eyes examined).

All the animals were found to be infected, including the six animals without ocular lesions visible during ophthalmoscopy. Infection was demonstrated by findings of Toxocara larvae in the liver and nervous tissue, or granulomatous lesions with fragments of larvae in the liver or lungs.

Table 1 - Results of indirect binocular ophthalmoscopy on 30 gerbils infected with Toxocara canis: observations in each infected animal 3, 10, 17, 24, 31 and 38 days after infection.

\begin{tabular}{|c|c|c|c|c|c|c|}
\hline \multirow[b]{2}{*}{$\mathrm{N}$} & \multicolumn{6}{|c|}{ Days after infection } \\
\hline & 3 & 10 & 17 & 24 & 31 & 38 \\
\hline 1 & $\mathrm{CH}, \mathrm{RH}, \mathrm{LM}, \mathrm{LT}_{\dagger}$ & nd & nd & nd & nd & nd \\
\hline 2 & $\mathrm{CH}, \mathrm{RH}$ & DUSN $\dagger$ & nd & nd & nd & nd \\
\hline 3 & $\mathrm{CH}$ & $\mathrm{Hwc}^{*}, \mathrm{CH}^{*}$ & VL, EL & VL, EL & VL, EL & RH, ViL, EL \\
\hline 4 & lnd & CH, RPEL & $\mathrm{CH}^{*}, \mathrm{RPEL}$ & $\mathrm{CH}^{*}, \mathrm{RPEL}$ & RPEL & RPEL \\
\hline 5 & lnd & $\mathrm{CH}$ & $\mathrm{CH}^{*}$ & $\mathrm{CH}^{*}$ & lnd & lnd \\
\hline 6 & lnd & $\mathrm{CH}, \mathrm{RH}$ & $\mathrm{CH}^{*}, \mathrm{RH}^{*}$ & $\mathrm{RH}^{*} \dagger$ & nd & nd \\
\hline 7 & lnd & $\mathrm{CH}$ & $\mathrm{CH}^{*}$ & $\mathrm{CH}^{*}$ & lnd & lnd \\
\hline 8 & lnd & RH, Hwc & $\mathrm{CH}, \mathrm{Hwc}$ & $\mathrm{CH}^{*}, \mathrm{RH}$ & $\mathrm{RH}, \mathrm{CH}$ & $\mathrm{RH}, \mathrm{CH}^{*}, \mathrm{RPEL}$ \\
\hline 9 & $\operatorname{lnd}$ & $\mathrm{CH}, \mathrm{Hwc}$ & $\mathrm{CH}^{*}, \mathrm{ViL}$ & $\mathrm{CH}^{*}$ & VL, RPEL & RPEL \\
\hline 10 & $\operatorname{lnd}$ & $\mathrm{CH}, \mathrm{RH}, \mathrm{EL} \dagger$ & nd & nd & nd & nd \\
\hline 11 & lnd & RH, EL, RD & ViL, RD & ViL, RD & ViL, RD & ViL, EL, RD \\
\hline 12 & lnd & RH, Hwc, EL, LM & $\mathrm{CH}, \mathrm{RH}^{*}$ & RPEL, LT & RPEL, LT & RPEL, LT \\
\hline 13 & $\operatorname{lnd}$ & $\mathrm{VH}$ & VH, Hwc, RH & $\mathrm{VH}^{*}, \mathrm{Hwc}^{*}, \mathrm{RH}^{*}$ & $\mathrm{VH}^{*}, \mathrm{CH}^{*}, \mathrm{RH}^{*}$ & $\mathrm{VH}^{*}, \mathrm{CH}^{*}, \mathrm{RH}^{*}$ \\
\hline 14 & lnd & lnd & EL, ViL & EL & EL & LT, RPEL \\
\hline 15 & lnd & lnd & $\mathrm{CH}, \mathrm{VL}$ & $\mathrm{CH}, \mathrm{VL}$ & $\mathrm{EL}, \mathrm{VL}$ & $\mathrm{EL}^{*}, \mathrm{VL}$ \\
\hline 16 & lnd & lnd & $\mathrm{CH}, \mathrm{RH}$ & $\mathrm{CH}^{*}, \mathrm{RH}^{*}$ & lnd & lnd \\
\hline 17 & lnd & lnd & CH, RPEL & CH, RPEL & $\mathrm{CH}^{*}, \mathrm{RPEL}$ & RPEL \\
\hline 18 & lnd & lnd & $\mathrm{CH}$ & $\mathrm{CH}$ & LT, RH & LT \\
\hline 19 & lnd & lnd & lnd & VLi & $\mathrm{VL}$ & lnd \\
\hline 20 & lnd & lnd & lnd & $\mathrm{CH}$ & $\mathrm{CH}^{*}, \mathrm{RPEL}$ & RPEL \\
\hline 21 & lnd & lnd & lnd & $\mathrm{RH}$ & $\mathrm{RH} \dagger$ & nd \\
\hline 22 & lnd & lnd & lnd & lnd & CH, RPEL & Hwc, RPEL \\
\hline 23 & lnd & lnd & lnd & lnd & EL & RPEL, EL* \\
\hline 24 & lnd & lnd & lnd & lnd & VH, CH, RH, ViL & $\mathrm{VH}^{*}, \mathrm{RH}^{*}, \mathrm{Hwc}$ \\
\hline 25 & lnd & lnd & lnd & $\operatorname{lnd} \phi$ & nd & nd \\
\hline 26 & lnd & lnd & lnd & lnd & lnd & lnd \\
\hline 27 & lnd & lnd & lnd & lnd & lnd & lnd \\
\hline 28 & lnd & lnd & lnd & lnd & lnd & lnd \\
\hline 29 & lnd & lnd & Ind & lnd & lnd & lnd \\
\hline 30 & lnd & lnd & lnd & lnd & lnd & lnd \\
\hline
\end{tabular}

$\mathrm{N}$ : number of animals, $\mathrm{CH}$ : choroidal hemorrhage, DUSN: diffuse unilateral subacute neuroretinitis, EL: retinal exudative lesions, Hwc: hemorrhage with white center, LM: larva migrans, LT: larval track, RH: retinal hemorrhage, RPEL: retinal pigment epithelium lesions, VH: vitreous hemorrhage, VL: vascular lesions, ViL: non-hemorrhagic vitreous lesions, RD: retinal detachment, $\uparrow$ : accidental death due to anesthesia, lnd: lesions were not detected, nd: not determined because animal was dead, *lesion in absorption. 
Table 2 - Frequency of ocular lesions observed in 30 gerbils infected with 100 eggs of Toxocara canis, which were subjected to indirect binocular ophthalmoscopy 3, 7, 17, 24, 31 and 38 days after infection.

\begin{tabular}{lcc}
\hline Type of lesion & Number & Percentage \\
\hline Choroidal hemorrhage & 18 & 60.0 \\
Retinal hemorrhage & 13 & 43.3 \\
Vitreous hemorrhage & 2 & 6.6 \\
Hemorrhages with white center & 6 & 20.0 \\
Retinal pigment epithelium lesions & 9 & 30.0 \\
Mobile larva or larval track & 4 & 13.3 \\
Retinal exudative lesions & 7 & 23.3 \\
Non-hemorrhagic vitreous lesions* & 5 & 16.6 \\
Vascular lesions & 3 & 10.0 \\
Retinal detachment & 1 & 3.3 \\
DUSN** & 1 & 3.3 \\
\hline
\end{tabular}

*includes fibrosis, membranes and presence of inflammatory cells. DUSN: diffuse unilateral subacute neuroretinitis
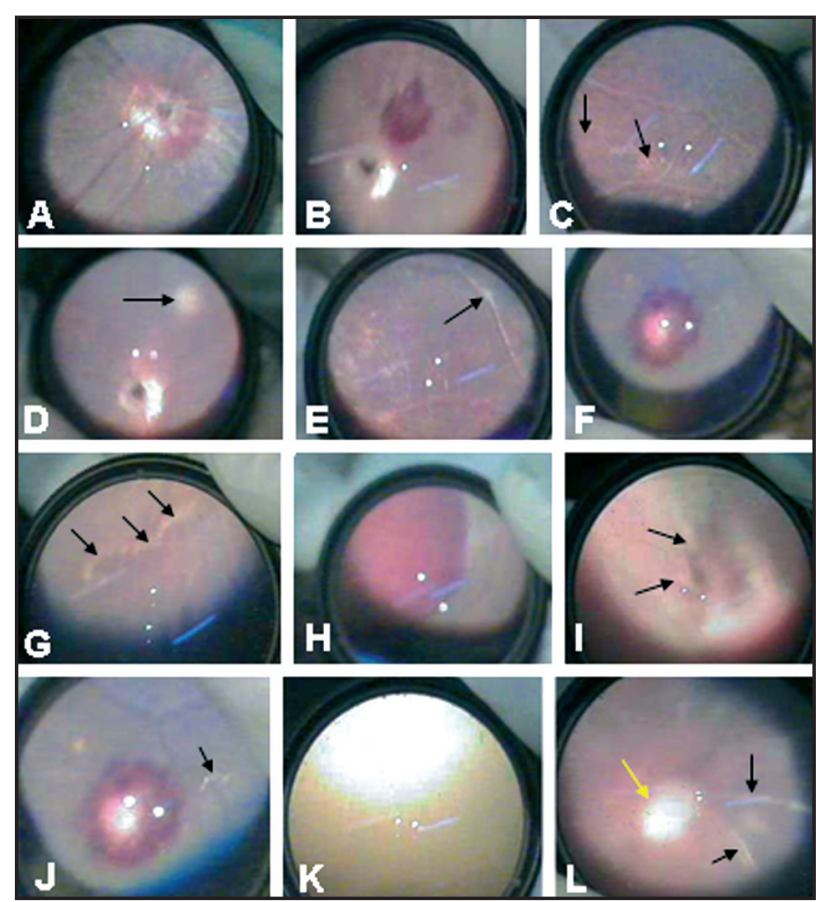

Figure 1 - Some representative images of lesions observed by means of indirect binocular ophthalmoscopy on gerbils infected with 100 embryonated eggs of Toxocara canis. A: Choroid hemorrhage. B: Retinal bemorrhage. C: Rarefaction of retinal epithelium (arrows). D: Exudative retinal lesion (arrow). E: Vasculitis (arrow). F: Retinal bemorrbage with white center. G: Larval track (arrows). H: Vitreous hemorrhage. I: Retinal detachment, represented by protrusion of retina (arrows) around the optic disk.J: Larva migrans (arrow). K: Vitreous opacity. L: Diffuse unilateral subacute neuroretinitis (DUSN): pallid optic disc (yellow arrow) and presence of vascular sheets indicating vasculitis (black arrows).

Histological examination of eyeballs was performed on 18 animals in which lesions had been observed by ophthalmoscopy. In 10 animals in which two sections per eye were analyzed, the lesions consisted of sparse, focal areas of retinal or choroid hemorrhage. However, in eight animals from which serial sections of the eyeballs were examined ( 40 sections per animal), lesions were observed in all segments of the eye, consisting especially of hemorrhages.
Focal superficial choroidal or retinal hemorrhages, sometimes with hemosiderin-loaded macrophages, were the main lesions observed in eight animals from which serial sections of the eyeballs were analyzed. Focal episcleritis and iridocyclitis, with neutrophils and eosinophils, were observed in three animals. Focal vasculitis and focal dacryoadenitis (both with eosinophils in the exudates) and eosinophilic granuloma in periocular tissues, were observed in one animal, in each lesion. Toxocara larvae in the retina were only observed in one animal, but without inflammatory cells around the larvae.

\section{DISCUSSION}

Our observations confirm that indirect ophthalmoscopy is easily performed on gerbils, especially among animals with pigmented skin. The ophthalmoscopy patterns confirm the similarity with the human retina that had already been demonstrated by means of optical microscopy ${ }^{1017}$.

Spontaneous retinal lesions were observed before infection and probably represented changes due to the aging process. Takayanagy et $\mathrm{al}^{27}$ reported only the presence of white spots in non-infected, threemonth-old gerbils. The gerbils we used were five to six months old and, for this reason, other spontaneous retinal lesions were observed. In fact, ophthalmoscopy on older gerbils (seven to twelve months old) has demonstrated frequent spontaneous degenerative lesions in the retina, in the form of white spots, retinal epithelial rarefaction and optic disc atrophy (Zanandrea LIDC, Pereira FEL, Oliveira GM, Abreu AS: unpublished data).

All the gerbils infected with 100 embryonated eggs of Toxocara presented migrating larvae or eosinophilic granulomas in tissues 38 days after infection, thus confirming the high susceptibility of these animals to Toxocara infection. Moreover, $80 \%$ of the animals presented retinal lesions, as observed by means of ophthalmoscopy, thus reinforcing other observations that have demonstrated that gerbils are highly susceptible to ocular lesions following Toxocara infection ${ }^{2}{ }^{27}$.

The frequency of ocular lesions that we have reported here was lower than the 90 to $95 \%$ reported by other authors that have reported ocular lesions in gerbils infected with Toxocara ${ }^{2}{ }^{327}$. These authors continued to perform ophthalmoscopy until 60 to 158 days after infection with large number of infective eggs $(1,000$ or more embryonated eggs per animal).

The lesions started soon after infection and were similar to what has been reported by other investigators who used gerbils for studies on ocular toxocariasis ${ }^{2327}$. These authors observed lesions three to five days after infection and, as we have reported here, hemorrhagic lesions were the most frequent type and presented signs of involution. However, the frequency of migrating larvae in the retina was lower in our observations: five (16.6\%) cases presented larvae or tracks of larva: four observed using ophthalmoscopy and one case using microscopy. Takayanagy et $\mathrm{al}^{27}$ reported findings of larvae through ophthalmoscopy in $80 \%$ of infected gerbils. This high frequency of larvae in the retina would be in relative to the number of inoculated eggs, as demonstrated in mice in which the number of eye invasions due to larvae was in direct relationship with the quantity of inoculum $^{12}$. 
As reported by other authors ${ }^{2327}$, we did not observe pseudotumoral appearance at the posterior pole or in peripheral granuloma.

Vascular abnormalities with a vasculitis pattern were observed in three animals and diffuse unilateral subacute neuroretinitis (DUSN) in one animal. Vasculitis was reported by Alba-Hurtado et $\mathrm{al}^{2}$, who accepted immune-mediated mechanisms for the pathogenesis of these lesions. DUSN has not been reported by other authors who studied ocular lesions in gerbils infected with Toxocara.

There was no difference in the frequency of lesions between males and females, thus demonstrating that gender did not influence the ocular lesions induced by Toxocara in gerbils, as seen in cases of ocular larva migrans among children ${ }^{2528}$.

In conclusion, our results demonstrated that ocular lesions are frequent in gerbils infected with Toxocara canis, even after infections that result in low larval burden. However, the lesions observed were mainly focal and sparse, and larvae or larval tracks were only observed by means of ophthalmoscopy in four (13.3\%) animals. Although ocular lesions were frequent in the eyeballs of the infected gerbils, most of the lesions observed were not similar to what is observed in human cases of ocular larva migrans. Only one animal presented a condition of DUSN, which has been described in cases of ocular larva migrans.

\section{REFERENCES}

1. Abe K, Shimokawa H, Kubota T, Nawa Y, Takeshita A. Myocarditis associated with visceral larva migrans due to Toxocara canis. Internal Medicine 41: 706-708, 2002

2. Akao N, Takayanagi TH, Suzuki R, Tsukidate S, Fujita K. Ocular larva migrans caused by Toxocara cati in Mongolian gerbils and a comparison of ophthalmologic findings with those produced by T. canis. Journal of Parasitology 86: 1133-1135, 2000.

3. Alba-Hurtado F, Tortora PJL, Tsutsumi V, Ortega-Pierres MG. Histopathological investigation of experimental ocular toxocariasis in gerbils. International Journal for Parasitology 30:143-147, 2000.

4. Bass JL, Mehta KA, Glickman LT, Eppes BM. Clinically inapparent Toxocara infection in children. New England Journal of Medicine 308: 723-724, 1983.

5. Azuma K, Yashiro N, Kinoshita T, Yoshigi J, Ihara N. Hepatic involvement of visceral larva migrans due to Toxocara canis: a case report--CT and MR findings. Radiation Medicine 20: 89-92, 2002.

6. Beaver PC. Parasitological reviews: Larva migrans. Experimental Parasitology 5: 587-621, 1956

7. Bertelmann E, Velhagen KH, Pleyer U, Hartmann C. Ocular toxocariasis. Diagnostic and therapeutic options Ophthalmologe 100:950-954, 2003.

8. Bhatia V, Sarin SK. Hepatic visceral larva migrans: evolution of the lesion, diagnosis, and role of high-dose albendazole therapy. American Journal of Gastroenterology 89: 624-627, 1994.
9. Brito T, Chieffi PP, Peres BA, Santos RP, Gayotto LCC, Viana MR, Porta G, Alves VA. Immunohistochemical detection of Toxocara antigen in human liver biopsies. International Journal of Surgical Pathology 2:117-123,1994.

10. Bytyqi AH, Layer PG. Lamina formation in the Mongolian gerbil retina (Meriones unguiculatus). Anatomy and Embryology 209:217-225, 2005

11. Despommier D. Toxocariasis: clinical aspects, epidemiology, medical ecology, and molecular aspects. Clinical and Microbiology Review 16:265-272, 2003.

12. Fenoy S, Ollero MD, Guillen JL, del Aguila C. Animal models in ocular toxocariasis. Journal of Helmintholology 75:119-124, 2001.

13. Gillespie SH, Dinning WJ, Voller A, Crowcroft NS. The spectrum of ocular toxocariasis. Eye 7:415-418, 1993

14. Glickman LT, Schantz PM. Epidemiology and pathogenesis of zoonotic toxocariasis. Epidemiological Reviews 3:230-250, 1981.

15. Good B, Holland CV, Taylor MRH, Larragy J, Moriarty P, O'Regan M. Ocular Toxocariasis in Schoolchildren. Clinical Infectious Diseases 39:173-178, 2004.

16. Hayashi E, Akao N, Fujita K. Evidence for the involvment of the optic nerve as a migration route for larvae in ocular toxocariasis of Mongolian gerbils. Journal of Helminthology 77: 311-315, 2003.

17. Imada H, Isomura G, Mivachi E. Blood supply to the retina and the lens in the gerbil (Meriones unguiculatus). Anatomical Science International 78: 36-41, 2003.

18. Magnaval JF, Glickman LT, Dorchies P. La Toxocarose, une zoonose helminthique majeure. Revue de Médicine Véterinaire 145:611-627, 1994

19. Magnaval JF, Glickman LT, Dorchies P, Morassin B. Highlights of human toxocariasis. The Korean Journal of Parasitology 39:1-11, 2001.

20. Magnaval JF, Malard L, Morassin B, Fabre R. Immunodiagnosis of ocular toxocariasis using Western-blot for the detection of specific anti-Toxocara $\operatorname{IgG}$ and CAP for the measurement of specific anti-Toxocara IgE. Journal of Helminthology 76: 335-359, 2002.

21. Molk R. Ocular toxocariasis: a review of the literature. Annals of Ophthalmology 15:216-231, 1983.

22. Moreira-Silva SF, Rodrigues MG, Pimenta JL, Gomes CP, Freire LH, Pereira FE Toxocariasis of the central nervous system: with report of two cases. Revista da Sociedade Brasileira de Medicina Tropical 37:169-174, 2004.

23. Musso C, Castelo JS, Tsanaclis AM, Pereira FE. Prevalence of Toxocara-induced liver granulomas, detected by immunohistochemistry, in a series of autopsies at a Children's Reference Hospital in Vitoria, ES, Brazil. Virchows Archiv für pathologische Anatomie und Physiologie und für klinische Medizin 450:411-417, 2007.

24. Nichols RL. The etiology of visceral larva migrans. I. Diagnostic morphology of infective second-stage Toxocara larvae. Journal of Parasitology 42:349-362, 1956.

25. Pawlowski, Z. Toxocariasis in humans: clinical expression and treatment dilemma. Journal of Helminthology. 75 :299-305, 2001.

26. Shields JA. Ocular toxocariasis. A review. Survey of Ophthalmology 28:361-381, 1984.

27. Takayanagi TH, Akao N, Suzuki R, Tomoda M, Tsukidate S, Fujita K. New animal model for human ocular toxocariasis: ophthalmoscopic observation. British Journal of Ophthalmolology 83:967-972, 1999.

28. Taylor MR. The epidemiology of ocular toxocariasis. Journal of Helminthology 75:109-118, 2001.

29. Taylor MR, Keane CT, O'Connor P, Girdwood RW, Smith H. Clinical features of covert toxocariasis. Scandinavian Journal of Infectious Diseases 19:693-696, 1987

30. Wilder HC. Nematode endophithalmitis. Transactions of the American Academy of Ophthalmology and Otolaryngology 55: 99-109, 1950 